\title{
Commentary: Colorectal lung metastases and the scalpel versus the beam
}

\author{
Christopher Cao, MBBS, PhD, ${ }^{\mathrm{a}, \mathrm{b}}$ and James Huang, $\mathrm{MD}^{\mathrm{a}}$
}

\footnotetext{
From the ${ }^{\text {a }}$ Thoracic Service, Department of Surgery, Memorial Sloan Kettering Cancer Center, New York, NY; and ${ }^{\mathrm{b}}$ Department of Cardiothoracic Surgery, Royal Prince Alfred Hospital, Sydney, Australia.

Disclosures: Authors have nothing to disclose with regard to commercial support.

Received for publication March 18, 2019; accepted for publication March 18, 2019; available ahead of print April $28,2019$.

Address for reprints: James Huang, MD, Memorial Sloan Kettering Cancer Center, 1275 York Ave, New York, NY 10065 (E-mail: huangj@mskcc.org).

J Thorac Cardiovasc Surg 2019;158:1244-5

$0022-5223 / \$ 36.00$

Copyright (c) 2019 by The American Association for Thoracic Surgery

https://doi.org/10.1016/j.jtcvs.2019.03.081
}

The popularization of stereotactic body radiotherapy (SBRT) for the treatment of pulmonary metastases has followed its success for primary lung cancers, with as many as $90 \%$ of European centers reporting the use of SBRT for pulmonary metastases. ${ }^{1}$ Colorectal cancers represent the second most common origin of pulmonary metastases, and Nelson and colleagues ${ }^{2}$ are to be commended for their analysis in this issue of the Journal comparing local recurrence rates of SBRT versus wedge resection for colorectal pulmonary metastases at the level of the individual nodule. In their study of 826 pulmonary nodules in 381 patients, SBRT was associated with a significantly higher incidence of local recurrence, with a hazard ratio of 3.28. This finding remained statistically significant when analysis was limited to propensity-matched cohorts, with a local recurrence rate of $14.1 \%$ at 2 years for nodules treated with wedge resection versus a rate of $29.4 \%$ for those treated with SBRT.

These findings are important but should be interpreted with caution. As Nelson and colleagues ${ }^{2}$ acknowledge, one of the major limitations of this nonrandomized observational study is the intrinsic selection bias behind the choice of SBRT versus surgery for any given nodule. Ninety percent of the patients in the study underwent surgery. Patients who underwent SBRT had solitary lesions, or 2 lesions at most; among patients who underwent wedge resection, none had solitary lesions, and some had 5 nodules. No information about the location of nodules was provided. It is possible that the nodules treated by SBRT were not amenable to wedge resection. Thus, whereas most nodules treated with wedge resection could possibly have been treated with SBRT, the converse may not be true. Other important factors in deciding between SBRT and surgery include performance status, comorbidities, and pulmonary function, but these variables were not included in the propensity model. Importantly, $66 \%$ of the nodules treated by SBRT were not histopathologically confirmed to be malignant, which raises questions about the observed SBRT).

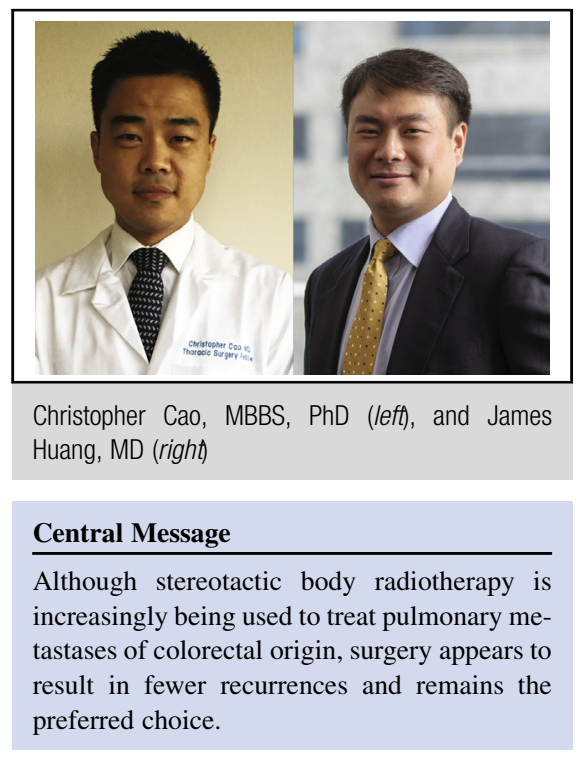

See Article page 1234.

outcomes in those patients. Patients deemed to have operable disease generally have fewer morbidities than those deemed to have inoperable disease and therefore treated with SBRT, and this bias may favor clinical outcomes for the surgical arm. Other limitations include the heterogeneity of the systemic therapy regimens in both groups and the relatively short radiographic follow-up (1.8 years for

If SBRT is indeed less efficacious than surgery for the treatment of colorectal cancer pulmonary metastases, an explanation may lie in the growing clinical evidence that colorectal pulmonary metastases are associated with higher radioresistance than non-small cell lung cancer and other histologic subtypes. ${ }^{3}$ This hypothesis is supported by Ahmed and colleagues, ${ }^{4}$ who calculated radiosensitivity indices with a 10-gene assay to differentiate the response of pulmonary metastases to SBRT on the basis of different histologic origins. Their study reported that rectal cancers in particular were relatively more radioresistant than breast, renal, and colon pulmonary metastases, and the biologically effective dosage for SBRT may therefore need to be increased to optimize local control of rectal metastases.

Ultimately, the findings of Nelson and colleagues ${ }^{2}$ suggest that surgery remains the preferred option relative to SBRT in operative candidates with colorectal metastases. 


\section{References}

1. Dahele M, Hatton M, Slotman B, Guckenberger M. Stereotactic body radiotherapy: a survey of contemporary practice in six selected European countries. Acta Oncol. 2015;54:1237-41.

2. Nelson DB, Tayob N, Nguyen Q-N, Erasmus J, Mitchell KG, Hofstetter WL, et al. Local failure after stereotactic body radiation therapy or wedge resection for colorectal pulmonary metastases. J Thorac Cardiovasc Surg. 2019;158: 1234-41.e16.

3. Thibault I, Poon I, Yeung L, Erler D, Kim A, Keller B, et al. Predictive factors for local control in primary and metastatic lung tumours after four to five fraction stereotactic ablative body radiotherapy: a single institution's comprehensive experience. Clin Oncol (R Coll Radiol). 2014;26:713-9.

4. Ahmed KA, Scott JG, Arrington JA, Naghavi AO, Grass GD, Perez BA, et al. Radiosensitivity of lung metastases by primary histology and implications for stereotactic body radiation therapy using the genomically adjusted radiation dose. J Thorac Oncol. 2018;13:1121-7. 